\title{
THE POST OPERATIVE PROGRESS OF A CHILD SUFFERING TRAUMATIC CEREBRAL LESION
}

\author{
C. W. LAW, M.B., F.R.C.S. (Neurosurgeon)*
}

\author{
AUDREY SHAVELL, B.A. Log (Rand)* \\ Senior Supervisor, University Speech, \\ Voice and Ilearing Clinic.
}

This case report is submitted to illustrate the progress made by a six-year-old child following a cerebral gun-shot lesion. It includes a copy of the neurosurgeon's notes on the case and the speech therapist's original assessment.

The child's vocabulary on initial testing consisted of only three words; detailed assessment revealed, however, an almost purely expressive aphasia. In spite of his restricted vocabulary and limited natural "speech" recovery, prognosis was considered hopeful.

\section{NEUROSURGEON'S NOTES:}

Report on Child P.D. Aged 6 years.

First seen and examined on the 19.1.57.

\section{CHIEF COMPLAINT:}

Child was accidentally shot by a 0.22 rifle at 5.30 p.m. on the 18.1 .57

\section{HISTORY :}

Child was able to walk for a short distance after the shooting but then collapsed. Was taken by a doctor to Bloemhof Hospital and later transferred to Wolmaranstad. The doctor undoubtedly saved this child's life, by the prompt administration of plasma and Dextron. At 11 p.m. telephonic arrangements were made for his admission to a Johannesburg Nursing Home, and the theatre was prepared for immediate operation. A pint of group $O$ blood was ordered at the same time.

\section{EXAMINATION:}

On admission at 3 a.m. I examined the child. Grossly shocked and of a waxy whiteness. Pulse 200 , thready, with questionable systolic pressure of 60 . Respiration exceedingly shallow, and variably rapid.

\section{Skull:}

There is an entrance wound 2" above the left Zygema and about 2" in front of the line of the external meatus. No powder marks visible.

The whole of the left side of the scalp was soft and bulging.

A jagged exit wound just to the left of the midline in the posterior parietal region was oozing blood clot and brain tissue.

The child could be roused by painful stimuli.

Pupils:

Absolutely pin point and fixed. Gross left sided facial paralysis. Left ear full of dried blood, no rupture seen. No bleeding from nose or mouth. Total flaccid paralysis of the right side. A saline cut-down was immediately set up and replaced with the blood on its arrival. Arrangements were made with the anaesthetist to commence operation as soon as condition improved slightly as Local Anaesthetic was not sufficient for cleaning purposes. Straight Portable X-Rays of skull taken with artery forceps used as a marker for the entry wound. There was a grossly comminuted disruptive fracture of the left side of the cranium.

\section{OPERATION NOTES}

The whole scalp was carefully cleaned, with spirits and spirit soap. The two wounds were separately cleaned with saline irrigation and Hydrogen peroxide. The exit wound was then carefully debrided as the amount of bruised tissue was tremendous.

The wounds were then joined by a slightly curved incision. Exuded brain tissue was present in the subgaleal space and contused oedematous brain oozed forth under great pressure between a number of opened fracture lines.

An attempt was made to preserve a pericranial layer. Loose fragments of bone were removed and other attached pieces which were displaced inwards were removed by nibbling. The dura was ruptured along the line of the wound and innumerable cortical vessels were ruptured and oozing continually. 
Steady work with suction and the electocautery gradually reduced the chaos to some order and the child's desperate condition improved. The wound arca was continually sluiced and warmed saline and $\mathrm{H}^{2} \mathrm{O}^{3}$ in view of the grave danger of infection.

Only grossly damaged cerebral tissue was removed, haemostasis achieved, gelfoam employed and the area protected by strips of gutta percha while an attempt to close the dura was made, but complete closure was impossible. Hitch sutures were employed to prevent further dura stripping.

A pericranium was reconstructed. The scalp was sutured in two layers and a drain inserted through a separate slab incision.

The child received $500 \mathrm{ccs}$ of whole blood on the table, and then I.V. saline was commenced. $\mathrm{He}$ received $1,000,000$ units of Penicillin on the table.

20.1.57 Child is holding his condition. Slight movement is present in the right arm, but to date no movement of the right leg. $\mathrm{He}$ is taking small arrount of fluid by mouth, so the I.V. drip has been discontinued.

22.1.57 The wound is well healed and sutures removed. No evidence of infection. There is one small area near the exit wound which is bulging, and arrangements for a protective guard have been made.

24.1.57 There has been no increase in size of the slight bulge in the scalp wound of the left parietal region, the midline comprehension is good, but no speech to date. Occasional movement has been seen to date in the right arm, but none in the right leg. To continue on Phenobarb gr. 1 t.d.s. Plastic repair to be considered very much later.

\section{UNIVERSITY SPEECH, VOICE AND} HEARING CLINIC REPORT

Name: P.D.

Age: 6 years.

Date of Examination: 25-3-57.

\section{Brief Medical History:}

Child was accidentally shot while travelling in a car approximately two months ago. The bullet entered the left temporal lobe and came out of the left occipital lobe. Sheared Motor Cortex and Broca's area. Angular Gyrus probably also damaged. Was left speechless with a complete right sided hemiplegia. Movement is gradually returning to the right side.

\footnotetext{
- Acknowledgement is made to Witwatersrand University Speech, Voice and Hearing Clinic for permission to publish the material on this case.
}

Physical Defect:

Right Hemiplegia. Is able to walk unassisted. Does not use right hand as an assisting hand. Can ride a tricycle alone.

Laterality:

Handedness: Prior to accident right. Has one brother who is left-handed. Now uses left hand entirely. Points, eats and uses left hand for all skilled activities.

Eyedness: Right on repeated testing.

Footedness: Not tested, refused to co-operate.

Intelligence: Prior to accident — apparently normal. Present functional intelligence appears unimpaired.

Educational History: Has never been to school or Nursery School, so estimate of degree of reten. tion of previous learned material could not be made.

Home Language: Afrikaans.

Present Vocabulary: Tong, hek, nee.

Comprehension of Spoken Language: He understands everything, according to parents.

Method of Communication at Ilome: By gesture.

Behaviour Problems: None, according to parents.

Oral Peripheral: Appearance and movement of all parts of the speech mechanism are normal. No evidence of paralysis or atrophy was seen. A detailed examination was not possible as the child was very nervous.

Form and Shape Perception: Appears intact. Has retained concepts of big and small and showed no confusion or trial and error behaviour on these tests.

Hand-Eye Co-ordination and Manual Manipulation: Good for his age. Has complete control of left hand.

Memory for Coloured Objects: Remembered 5 out of 8 single colours. Failed memory for double and three colour sequences, but immediately saw that his responses were incorrect and spontaneously corrected them.

Pictorial Associations: The child was shown 12 sets of pictures, each set consisting of 4 single pictures and 2 mounted pictures with a recess for a third. He was required to select from the single pictures the one that was associated with the mounted picture, e.g.

aeroplane, bird, $\longrightarrow$, car, engine, kite, antelope.

He scored 8out of 12 , which is at the 7 year level. $\mathrm{He}$ is also obviously capable of making associations. 
TESTS FOR PRIMARILY RECEPTIVE APHASIC DISTURBANCES:

A.-Agnosias:

1.Visual Agnosias:

(a) Common objects intact.

(b) Pictures intact.

(c) Colours intact.

(d) Forms intact.

\section{Auditory Agnosias:}

(a) Recognition of Sounds: coughing, whistling, humming, etc. Refused to co-operate.

(b) Word Identification: All correct.

3. Tactile Agnosias: (Astereognosis)

Left hand - intact.

Right hand - intact.

\section{B. Aphasias:}

1. Auditory verbal comprehension: Answers to questions by gesture or pointing, or following commands, intact.

2. Ability to remember and execute complex (double) commands intact.

\section{TESTS FOR PREDOMINANTLY EXPRESSIVE DISTURBANCES:}

A. Apraxias:

1. Non-verbal:

(a) Body parts. Intact.

(b) Simple skills. Intact.

(c) Pretended action. Intact.

2. Verbal - Repetitive Speech:

(a) Repetition of numbers.

(b) Repetition of words.

(c) Repetition of sentences.

Was unable to repeat any of above material. Was acutely aware of his own inadequacies and reacted in a shy manner, burying his head in his father's lap and refusing to look at the therapist or the testing material.

B. Aphasias:

1. There is no automatic speech or singing present.

2. Other expressive language activities like spelling, writing from dictation, arithmetic, oral reading, clock setting were not tested, as the child has not had the opportunity of learning them prior to the accident.

\section{CONCLUSIONS:}

1. This child appears on initial testing to be an almost pure expressive (motor) aphasic.

2. Intelligence prior to the accident is not known, but from the parents' reports seems to have been normal. No intellectual retardation appears to have taken place.

3. None of the typical signs of the "brain-injured child", viz. catastrophic reaction, perseveration lack of emotional control, hyper-irritability and distractability were seen during his two-hour observation at this clinic.

\section{PROGNOSIS:}

Appears to be favourable in view of his age and the apparent absence of the disturbing characteristics usually found in the brain-injured child. Accurate prognosis for the regaining of language and speech is always difficult to make, but after a trial period of intensive therapy it will be possible to comment on factors such as speed of learning, retention of learned materials, fatigueability, etc.

\section{MisS BESSIE DEMBO}

\author{
54 WINGATE MANSIONS \\ Cor. SMIT \& NUGGET STREETS, \\ HOSPITAL HILL, JOHANNESBURG \\ Phone 44-0860
}

Typing and Roneoing Undertaken, especially

Theses and Studients' Notes. 


\section{PRESENTATION OF CASE TO GROUP OF NEUROLOGISTS}

At the first meeting at which he was presented, it was considered that should speech return, it would be at the best indifferent. As far as the right hand was concerned, the opinion was, that at the very best, this would be merely a support. An interesting medical question was as to whether the plate should be inserted at this stage, in view of the fact that further skull growth would make the plate too small in the future, but in view of his extreme activity it was decided that he should be afforded the added protection as he continually disregarded his protective skull cap.

\section{FOLLOW.UP REPORT}

\section{MEDICAL \& SURGICAL CONDITION:}

Post-operative recovery was uneventful in that he has never suffered from fits, dizziness, double vision, headaches, etc. $\mathrm{He}$ wore an alluminium protective cage until AUGUST, 1958.

On 14.8.58, a plastic plate was inserted into the left side of the head. He was hospitalised for only five days, has since worn no protective head covering. He was referred to an Orthopedic Surgeon in July 1957 and was fitted with a fulllength brace for the right leg which he wore for two months.

\section{SPEECH AND LANGUAGE:}

Because of transport difficulties it was not possible to arrange immediate therapy for this child; it was therefore decided to give the parents a home programme and observe the natural recovery. Six months after the operation, he started using single words. This was soon followed by the use of sentences. General vocabulary increased.

At the last re-check (14-10-58), it was found that he has a complete vocabulary and converses in full sentences. When fatigued he occasionally omits a verb, e.g. Ek nie skool toe gaan for Ek wil nie skool tot gaan nie.

He has full and complete movement of all parts of the speech mechanism, diadochokinesis normal, basic functions normal, no articulatory errors. Memory and concentration are excellent. He is a very observant child, playful, has a long attention span and mixes well with other children, both siblings and school peers.

\section{HEMIPLEGIA}

Still has a slight limp and has only recently begun to use the right hand in a few activities, e.g. when he wakes in the morning, stretches both arms up and recently began opening right hand. He does not use the right hand as an assisting hand. All skilled activities are quickly and accurately performed with the left hand. He writes very well with his left hand and according to his father has the best hand-writing of all the children in the family.

\section{SCHOOLING :}

He commenced school in January, 1958 and is one of the best pupils in his class. He manages all subjects easily except for arithmetic. He appears to have some difficulty in grasping number concepts. This must be watched as it may be an indication of impairment of the abstract attitude as defined by Goldstein.

$\mathrm{He}$ gets on extremely well with the children at school and is very fond of school.

\section{CONCLUSION:}

This case has been reported in some detail, to illustrate the importance of making a detailed assessment of speech and language in Aphasic patients. When first seen, eight weeks after the accident, the child's vocabulary consisted of three words. Prognosis might therefore have superficially appeared to be very poor. Detailed testing revealed, however, a much brighter picture and subsequent development has attested to the accuracy of the original diagnosis and prognosis.

\section{This advertisement sponsored by}

\section{GEORGE INGRAM CHEMIST}

\author{
and
}

NEMZER'S FISHERIES 